\title{
pH Salival, Capacidad Buffer, Proteínas Totales y Flujo Salival en Pacientes Hipertensos Controlados Usuarios de Diuréticos
}

\author{
Salivary pH, Buffer Capacity, Total Proteins and Salivary Flow \\ in Controlled Hypertensive Patients Diuretic Users
}

Samuel Muñoz L.* \& Carmen Gloria Narváez**

MUÑOZ, L. S. \& NARVAEZ, C. G. pH salival, capacidad buffer, proteínas totales y flujo salival en pacientes hipertensos controlados usuarios de diuréticos. Int. J. Odontostomat., 6(1):11-17, 2012.

RESUMEN: La hipertensión arterial (HTA) es una enfermedad cardiovascular que padece gran parte de la población mundial y nacional, alcanzando en Chile un 26,9\% en el año 2010. El objetivo fue determinar pH salival, capacidad buffer, proteínas totales y flujo salival, en pacientes hipertensos controlados usuarios de diuréticos. Se analizaron 14 muestras de saliva no estimulada de pacientes hipertensos controlados con diuréticos y 10 muestras de saliva no estimulada de personas que no padecían enfermedades sistémicas y no tomaban medicamentos, los valores obtenidos de $\mathrm{pH}$ salival, capacidad buffer, flujo salival y proteínas totales fueron determinados en ambos grupos. La mediana obtenida en las muestras de hipertensos controlados con diuréticos, para el pH salival fue de 6,83; para la capacidad buffer fue 4,86; para el flujo salival fue $0,55 \mathrm{ml} / \mathrm{min}$ y para las proteínas totales salivales fue de $1,09 \mathrm{~g} / \mathrm{dL}$. Para el grupo de pacientes sanos la mediana fue de 6,88 para el $\mathrm{pH} ; 4,25$ para la capacidad buffer; $1,8 \mathrm{ml} / \mathrm{min}$ para el flujo salival y 0,29 $\mathrm{g} / \mathrm{dL}$ para las proteínas totales salivales. Además, no se encontró asociación entre el flujo salival ( $r s=0,425$ ), capacidad buffer ( $r s=0,283$ ) y concentración de proteínas $(r s=0,245)$ con la dosis del diurético $(p>0,05)$. Se encontró que existieron diferencias estadísticamente significativas en el flujo salival y la concentración de proteínas salivales entre el grupo de pacientes hipertensos y de pacientes sanos (U Mann-Wthitney $\mathrm{P}<0,005)$. No existían diferencias estadísticamente significativas de $\mathrm{pH}$ salival y capacidad buffer entre pacientes hipertensos controlados y pacientes sanos ( $U$ Mann-Wthitney $P>0,005$ ). Los pacientes que sufren HTA y están siendo controlados con diuréticos tienen una disminución del flujo salival y un aumento de la concentración de proteínas, no viéndose afectadas las variables de $\mathrm{pH}$ y capacidad buffer. ticos.

PALABRAS CLAVE: pH salival, flujo salival, capacidad buffer, proteínas totales, hipertensión arterial, diuré-

\section{INTRODUCCIÓN}

La hipertensión arterial (HTA) es una enfermedad cardiovascular que padece gran parte de la población mundial y nacional, afectando en el año 2004 a un $21,7 \%$ de la población de nuestro país y en el año 2010 la prevalencia de esta enfermedad aumento a un 26,9\% (Ministerio de Salud, 2010). Para tratarla, existe una gran variedad de medicamentos como los diuréticos, betabloqueantes, antagonistas del calcio, inhibidores de la enzima convertidora de la angiotensina, y otros grupos más pequeños donde están incluidos vasodilatadores y alcaloides totales (Reverte Cejudo, 1998). Dentro de estos medicamen- tos, los diuréticos son considerados como primera opción de tratamiento y cumplen un eficaz rol en el control de la hipertensión generada por exceso de volumen, la HTA de adultos mayores, la HTA sistólica y la HTA con insuficiencia cardiaca (Ministerio de Salud, 2006). Aumentan la eliminación de orina y sodio del organismo, lo que sirve para bajar la presión arterial, tanto por el líquido perdido como por la disminución de la resistencia al flujo sanguíneo (Gallardo, 1997). En general son bien tolerados y su efecto hipotensor se produce con dosis bajas, evitando con ello la aparición de efectos secundarios. Existen del tipo de las

\footnotetext{
* Alumno Tesista. Facultad de Odontología, Universidad del Desarrollo, Concepción.

* Tutor de Tesis. Bioquímico, MSC en Educación Superior. Facultad de Odontología, Universidad del Desarrollo Concepción.
} 
tiazidas como la hidroclorotiazida, las que actúan a nivel del asa de Henle como la furosemida y las ahorradoras de $\mathrm{K}+$ como la espironolactona (Reverte Cejudo). Esta aumentada eliminación de líquidos, puede afectar directamente al volumen de saliva excretado por las glándulas salivales de la cavidad oral. Esto podría llevar a que sus funciones especializadas tales como, protección de la mucosa oral y dientes, rol antibacteriano, facilitador de la alimentación, limpiador por arrastre y su rol buffer estén de alguna forma alterados, pudiendo hacer más difícil y poco placentero el diario vivir (Kaplan, 1993). Actualmente no existen estudios que demuestren si existe alguna relación entre el tratamiento de la HTA con el uso de diuréticos y el $\mathrm{pH}$ salival, flujo salival, capacidad buffer y flujo salival de las personas, lo que podría generar una amplificación en la perspectiva de que gran parte de las enfermedades sistémicas, tienen repercusiones a nivel de la cavidad oral. La alteración de estos parámetros dentro de la saliva podría generar una mayor cantidad no sólo de caries, sino que también enfermedades de origen fúngico, enfermedades periodontales y queilitis angular (Screebny, 1992).

Este tipo de medicamento al ser capaz de disminuir la cantidad de fluidos en el organismo, puede afectar la cantidad de saliva excretada, por lo que este estudio busca determinar si estos medicamentos son capaces de afectar la concentración de proteínas totales, $\mathrm{pH}$ salival, capacidad buffer y el flujo salival en pacientes hipertensos controlados.

\section{MATERIAL Y MÉTODO}

Se realizó un estudio correlacional, donde se reclutaron a pacientes hipertensos controlados de la Facultad de Odontología de la Universidad del Desarrollo de Concepción, durante el año 2011. Los criterios de inclusión fueron pacientes con HTA controlada sólo con diuréticos o con diuréticos asociados a otro fármaco para controlar la HTA y pacientes que asistan a la Clínica de Odontología de la Facultad de Odontología de la Universidad del Desarrollo de Concepción. Los criterios de exclusión fueron pacientes con HTA controlada con diuréticos asociados a otro fármaco que no forme parte de los medicamentos para controlar la HTA y pacientes que padezcan otras enfermedades sistémicas. A los pacientes que estaban controlando su HTA con medicamentos del tipo diuréticos, se les hizo firmar un consentimiento informado previo a su participación en el estudio, luego se tomaron sus datos básicos y se le adjudicó un número. Posterior a esto, se tomaron las muestras de saliva no estimulada durante 1 minuto, las que fueron depositadas en tubos de ensayo plásticos graduados de $15 \mathrm{ml}$ con tapa rosca, enumerados con el respectivo número de cada paciente. Una vez obtenidas las muestras de los pacientes, estas fueron transportadas al laboratorio de la universidad en un contenedor con hielo para sus respectivos análisis. Allí se midió la cantidad de $\mathrm{mL} /$ minuto de saliva no estimulada. Posterior a esto, a cada muestra, se le midió el pH salival utilizando un $\mathrm{pH}$ metro digital tipo lápiz con ATC de display grande resistente al agua (Sper Scientific) que fue previamente calibrado consoluciones buffers de $\mathrm{pH} 4,0$ y 6,88 , y se anotó en la ficha correspondiente. Para determinar la capacidad buffer de las muestras de saliva no estimulada, se utilizó el método de titulación de ácido clorhídrico, método de Ericsson $(0,005 \mathrm{M})$ y para esto se obtuvieron muestras de $1 \mathrm{~mL}$ (pertenecientes a las muestras de cada paciente) con una micropipeta $1 \mathrm{~mL}$ (Echromtech) las que se depositaron en tubos de ensayo de vidrio. A cada muestra de $1 \mathrm{ml}$ de saliva, se le adicionó $3 \mathrm{ml}$ de $\mathrm{HCl}(0,005 \mathrm{M})$, posterior a esto, se esperó durante 20 min (Ericsson, 1959), obteniendo de esta forma la capacidad buffer salival de cada paciente. Para determinar la concentración de proteínas totales de cada muestra se utilizó el método de Biuret. Para esto fue necesaria la construcción de una curva de calibración, la que se hizo utilizando suero patrón de una concentración de $5.78 \mathrm{~g} / \mathrm{dL}$, del cual se realizó una dilución seriada usando $500 \mu \mathrm{l}$ de suero patrón y $500 \mu \mathrm{l}$ de suero fisiológico, en diluciones $1 / 2,1 / 4,1 / 8$, $1 / 16,1 / 32,1 / 64,1 / 128,1 / 256$ de la concentración inicial del suero patrón, que fueron depositadas en tubos de ensayo numerados. De cada una de estas diluciones, se extrajeron $20 \mu \mathrm{l}$ que fueron mezclados con 2 $\mathrm{ml}$ de reactivo de Biuret en otro tubo de ensayo también numerado. Posteriormente, luego de haber mezclado los $20 \mu \mathrm{l}$ de cada una de las diluciones con el reactivo de Biuret en tubos de ensayo numerados, estos tubos fueron puestos durante 20 minutos en una estufa - incubadora (Quimix) a $37^{\circ} \mathrm{C}$. Una vez pasado este lapso, se extrajo $1 \mathrm{ml}$ de cada una de estas muestras que fueron depositados en cubetas para espectrofotómetro, también numeradas. Luego, mediante un espectrofotómetro con un rango de longitud de onda 200 a $1000 \mathrm{~nm}$ lámpara de deuterio display LCD (Echromtech) se leyó la absorbancia a $540 \mathrm{~nm}$, de cada una de estas muestras, obteniendo el valor de la absorbancia. Con estos valores, se construyó la curva de calibración. Con la curva de calibración ya construida, se procedió a medir la concentración de 
proteínas de cada una de las muestras de saliva obtenida de los pacientes. La muestra de saliva fue homogenizada utilizando el agitador Vortex (Boeco), luego, se extrajeron $20 \mathrm{ml}$ de cada una de estas muestras las que fueron mezcladas con $2 \mathrm{ml}$ de reactivo de Biuret. Finalmente, $1 \mathrm{ml}$ del total de la muestra fue depositado en cubetas de espectrofotómetro y medida su absorbancia en el espectrofotómetro a $540 \mathrm{~nm}$.

Se realizó el mismo procedimiento de análisis para las muestras obtenidas de pacientes que no padecían ninguna enfermedad y que no estaban bajo algún tratamiento médico.

Habiendo determinado los datos que se requerían para realizar este estudio, se procedió a analizar los resultados, además de compararlos con los valores de referencia de cada una de las variables estudiadas. Los datos fueron tabulados en Microsoft Excel 2010 y, luego exportados a SPSS 17. Se utilizaron medidas de tendencia central tales como media y mediana; de dispersión tales como mínimo, máximo y desviación típica. Se elaboraron gráficos de dispersión y se calculó la correlación mediante Rho de Spearman, ya que no se cumplió la normalidad que fue verificada mediante test de Shapiro Wilks. Además, se realizó comparación de las variables estudiadas de los pacientes que consumían diuréticos y los sanos, mediante la U de Mann - Whitney.

\section{RESULTADOS}

Se muestreó un total de 24 pacientes, 14 de ellos padecían sólo HTA y estaban siendo controlados con medicamentos del tipo diurético, los 10 pacientes restantes no padecían enfermedades sistémicas ni estaban consumiendo algún medicamento.

En los pacientes con HTA, se obtuvieron medidas de tendencia central y de dispersión para el $\mathrm{pH}$ salival, capacidad buffer, flujo salival, proteínas totales y dosis del diurético (Tabla I).

Se evaluó la asociación entre la dosis de diurético con el pH salival, capacidad buffer, flujo salival y concentración de proteínas de la saliva. Se encontró una asociación medianamente positiva con el flujo salival rs $=0,425$ (Fig. 1), pero sin alcanzar a ser significativa (valor - $p=0,130$ ); se encontró una asociación levemente positiva con la capacidad buffer $r s=0,283$ (Fig. 2) y para la concentración de proteínas, $r s=0,245$ (Fig. 3), pero sin alcanzar a ser significativas (valor $p=0,327$ y 0,4 ; respectivamente). No se encontró asociación entre el $\mathrm{pH}$ salival y la dosis de diurético rs = 0,35 (valor $-p=0,905$ ) (Fig. 4).

En los pacientes que no padecían HTA y que no consumían ningún medicamento, se obtuvieron

Tabla I. Pacientes con HTA controlados con diuréticos.

\begin{tabular}{lccccc}
\hline & Media & Mediana & Mínimo & Máximo & D.T $^{*}$ \\
\hline pH salival & 4,62 & 0,55 & 5,76 & 7,45 & 0,29 \\
Capacidad buffer & 4,61 & 4,86 & 3,5 & 5,96 & 0,78 \\
Flujo salival $(\mathrm{ml} / \mathrm{min})$ & 0,57 & 0,55 & 0,2 & 1,1 & 0,29 \\
Proteínas salivales $(\mathrm{g} / \mathrm{dL})$ & 1,49 & 1,09 & 0,31 & 3,48 & 0,92 \\
Dosis diurético $(\mathrm{mg})$ & 18,92 & 12,5 & 12,5 & 40 & 8,58 \\
\hline
\end{tabular}

*D.T: Desviación típica

Tabla II: Pacientes sanos.

\begin{tabular}{lccccc}
\hline & Media & Mediana & Mínimo & Máximo & ${\mathrm{D} . T^{*}}^{*}$ \\
\hline pH salival & 6,86 & 6,88 & 6,41 & 7,48 & 0,31 \\
Capacidad buffer & 4,15 & 4,25 & 3,02 & 4,93 & 0,61 \\
Flujo salival (ml/min) & 1,92 & 1,8 & 1,6 & 3 & 0,4 \\
Proteínas salivales (g/dL) & 0,46 & 0,29 & 0,02 & 1,32 & 0,44 \\
\hline
\end{tabular}

${ }^{*}$ D.T: Desviación típica 
medidas de tendencia central y de dispersión para el $\mathrm{pH}$ salival, capacidad buffer, flujo salival y proteínas totales (Tabla II).

Existe una diferencia estadísticamente significativa entre el flujo salival de pacientes que padecían HTA controlada con diuréticos y los pacientes sanos

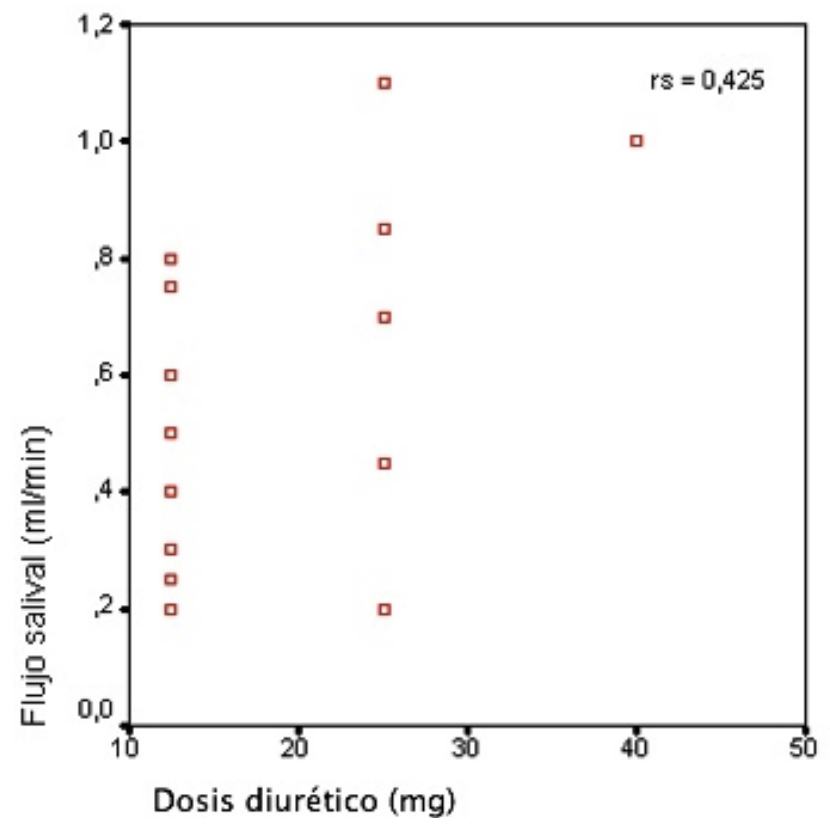

Fig. 1 Gráfico de dispersión para flujo salival y dosis de diurético.

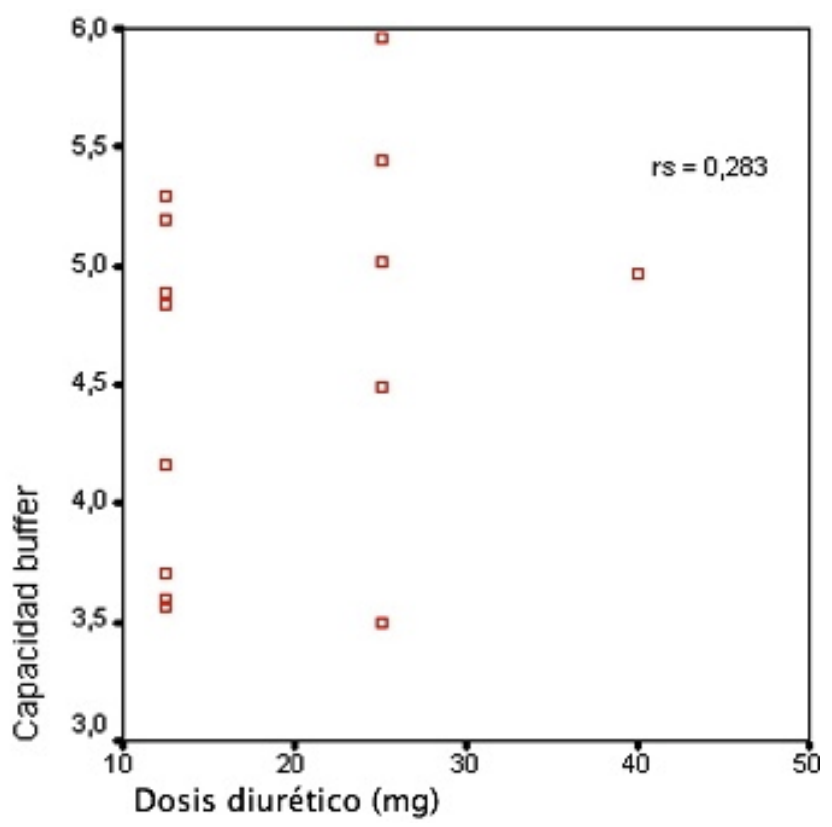

Fig. 2 Gráfico de dispersión para capacidad buffer y dosis de diurético. $(p=0,00)$ (Fig. 5). También, se encontró, una diferencia estadísticamente significativa entre la concentración de proteínas totales salivales $(p=0,03)$ (Fig. 6). Para las variables de $\mathrm{pH}$ salival y capacidad buffer, no existían diferencias estadísticamente significativas $(p=$ 0,651 y $p=0,151$ respectivamente).

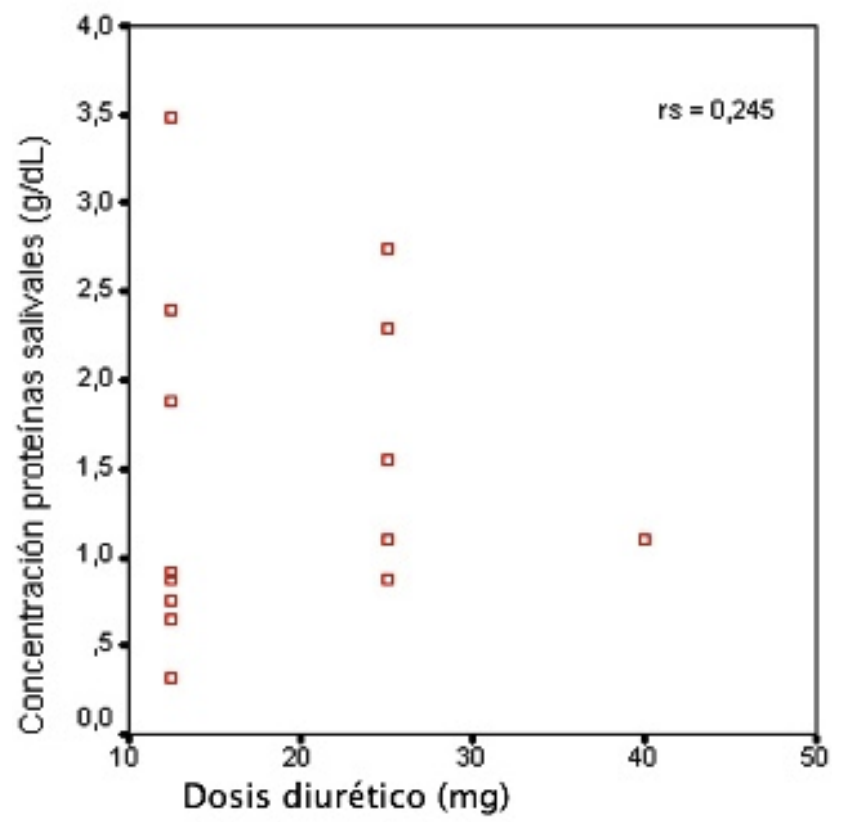

Fig. 3 Gráfico de dispersión para concentración de proteínas salivales y dosis de diurético.

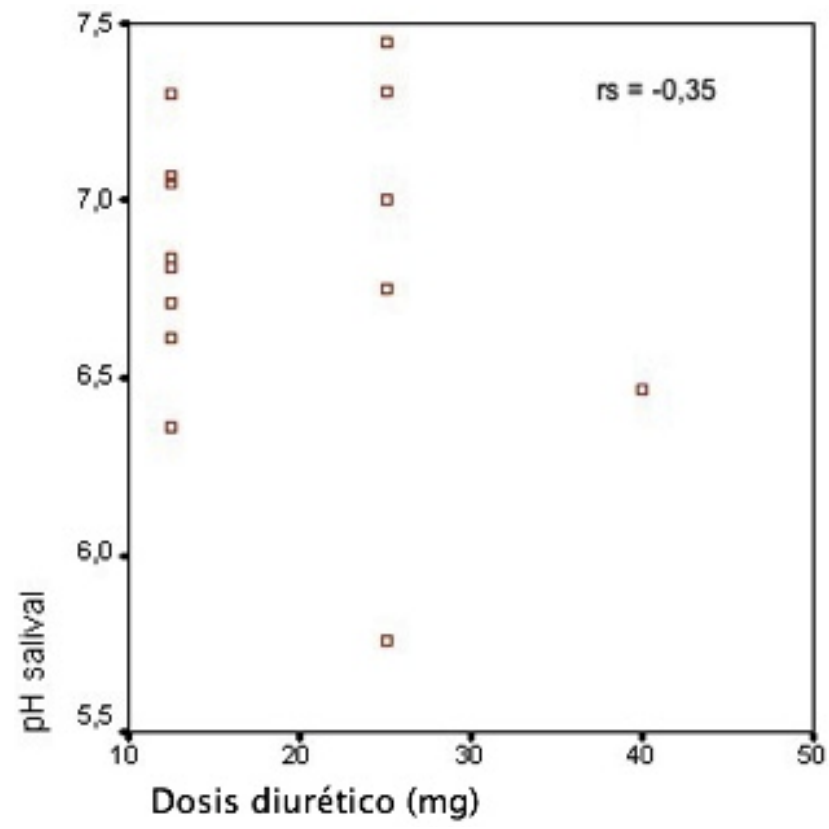

Fig. 4 Gráfico de dispersión para pH salival y dosis de idiurético. 
MUÑOZ, L. S. \& NARVAEZ, C. G. pH salival, capacidad buffer, proteínas totales y flujo salival en pacientes hipertensos controlados usuarios de diuréticos. Int. J. Odontostomat., 6(1):11-17, 2012.

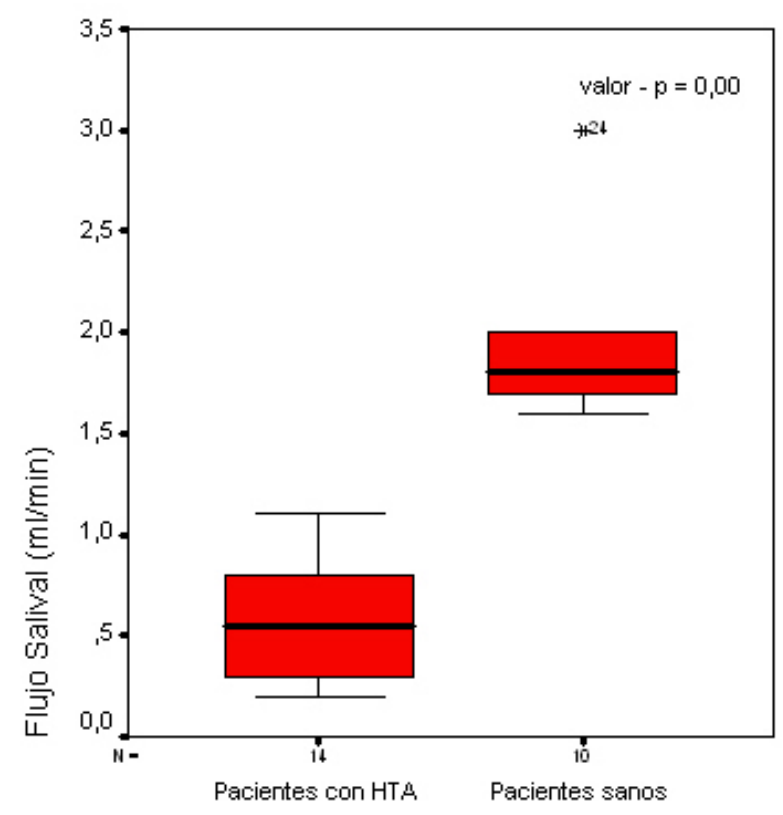

Fig. 5. Diagrama de cajas para el flujo salival en pacientes con HTA y pacientes sanos.

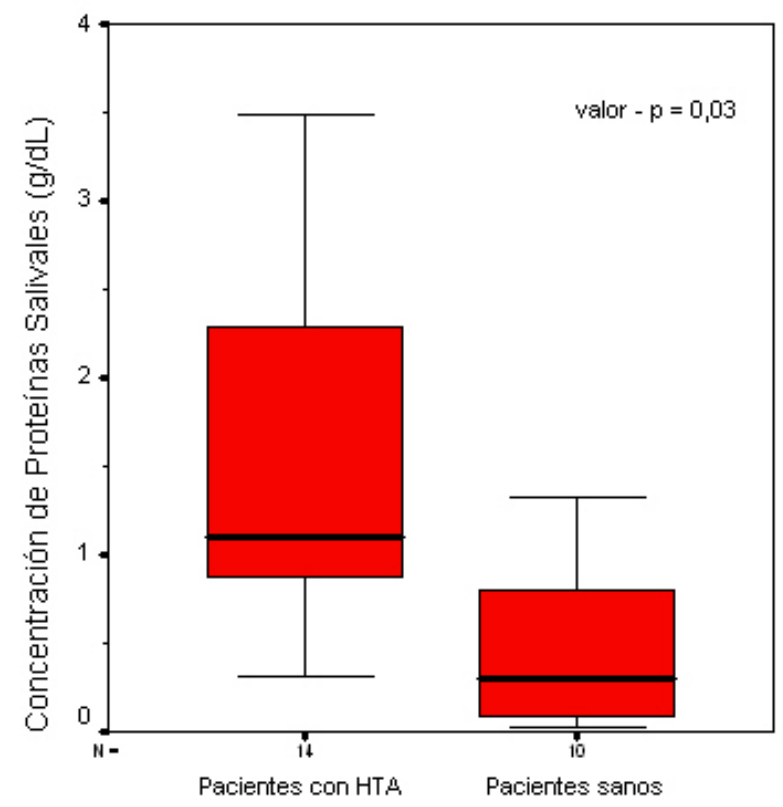

Fig. 6 Diagrama de cajas para concentración de proteínas salivales en pacientes con HTA y pacientes sanos.

\section{DISCUSIÓN}

Los hallazgos de este estudio sugieren que existe asociación, pero sin alcanzar a ser significativa entre la dosis del diurético y capacidad buffer, concentración de proteínas de la saliva y el flujo salival, lo que concuerda

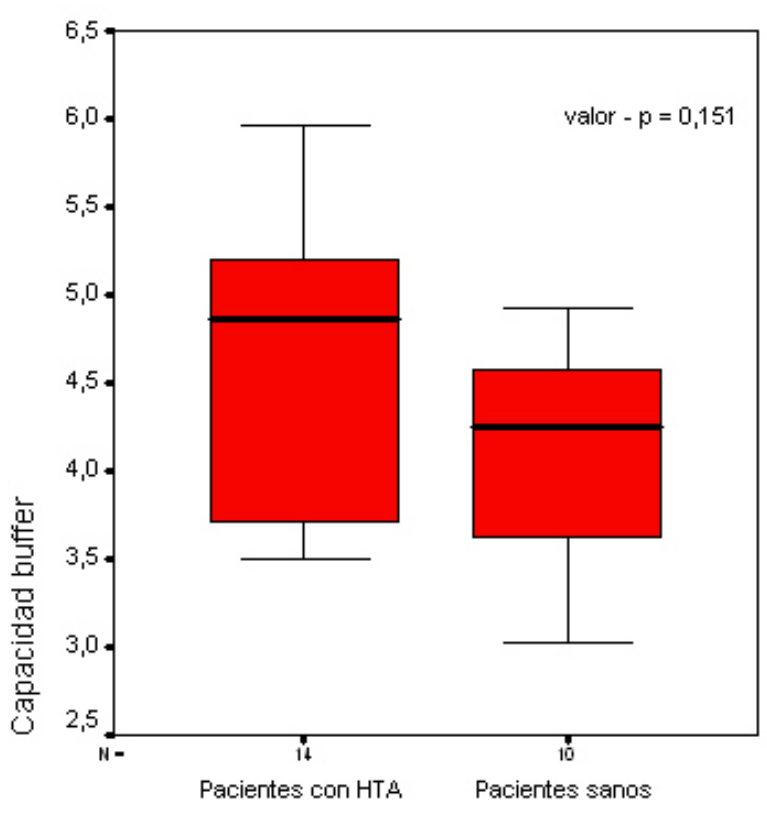

Fig. 7 Diagrama de cajas para la capacidad buffer en pacientes con HTA y pacientes sanos.

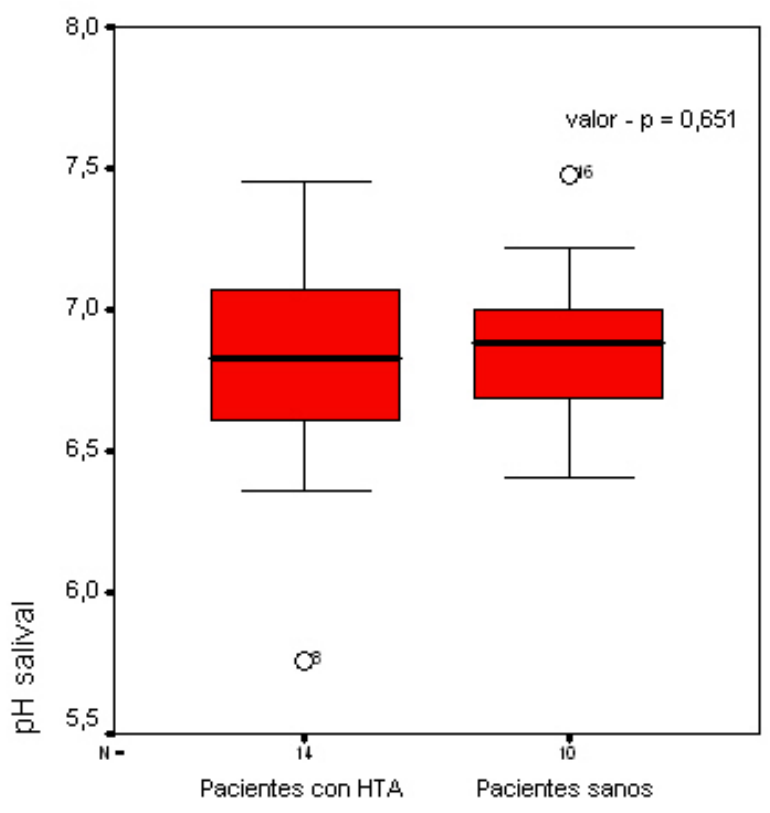

Fig. 8 Diagrama de cajas para el pH salival en pacientes con HTA y pacientes sanos.

con otros resultados en los que no se detectó un efecto de la bendroflumetiazida en el flujo salival no estimulado (Nedefors, 1989). Además, se encontró que no existe asociación entre dosis del diurético y el pH salival. 
El valor promedio obtenido para el $\mathrm{pH}$ de saliva no estimulada de pacientes sanos $(6,86 \pm 0,32)$, concuerda con el obtenido por Muñoz-Montagud (6.79 \pm 0.28 ), sin embargo, el valor promedio para flujo salival encontrado $(1,8 \pm 0,4 \mathrm{ml} / \mathrm{min})$, no concuerda con los resultados del mismo estudio $(0.48 \mathrm{ml} / \mathrm{min})$ (FenollPalomares et al., 2004). El flujo salival en pacientes sanos $(1,8 \pm 0,4 \mathrm{ml} / \mathrm{min})$, tampoco concuerda con el obtenido por Banderas-Tarabay $(0,39 \pm 0,29 \mathrm{ml} / \mathrm{min})$ (Banderas-Terabay et al., 1997). En cuanto a la concentración de proteínas salivales el valor promedio obtenido en pacientes sanos $(0,29 \pm 0,44 \mathrm{~g} / \mathrm{dL})$ no concuerda con el obtenido por Zárate $(0,0008 \mathrm{~g} / \mathrm{dL}$ ) (Zárate et al., 2004), tampoco concuerda con el obtenido por Banderas-Tarabay $(0,137 \mathrm{~g} / \mathrm{dL})$ (Banderas-Terabay et al.) ni el obtenido por Preethi et al. $(0,0052 \mathrm{~g} / \mathrm{dL})$ (Preethi et al., 2010). Los métodos utilizados por Preeti et al.; Zárate et al. y Banderas-Terabay et al. son métodos basados en el mismo principio utilizado en éste estudio, pero con diferencias de manipulación de la muestra, lo que puede explicar las diferencias.

También se encontró que si existe una diferencia estadísticamente significativa en el flujo salival y concentración de proteínas salivales entre personas hipertensas que están siendo controladas con diuréticos y las personas sanas que no consumen medicamentos (valor $-p<0,05)$. Esto alcanzando valores de diferencia entre los flujos de saliva no estimulada hasta $1,35(\mathrm{ml} / \mathrm{min})$ y hasta $1,03(\mathrm{~g} / \mathrm{dL})$ de proteínas totales salivales. Esta diferencia que se encontró en el flujo salival y la concentración de proteínas totales se debe al actuar de los diuréticos, aumentando la eliminación de líquidos y sales del organismo. Al provocar la disminución de los fluidos corporales, disminuye el flujo salival y, en consecuencia, aumenta la concentración de proteínas salivales.

Debido a la falta de información científica con respecto al tema, no se pueden realizar comparaciones de las variables en estudio para pacientes con HTA usuarios de diuréticos para determinar si es que los valores obtenidos son los normales o están alterados.

Sería importante realizar este estudio con un mayor número de pacientes con HTA que estén siendo controlados con diuréticos, haciendo diferenciación en género y edad.

MUÑOZ, L. S. \& NARVAEZ, C. G. Salivary pH, buffer capacity, total proteins and salivary flow in controlled hypertensive patients diuretic users..Int. J. Odontostomat., 6(1):11-17, 2012.

ABSTRACT: Introduction: Hypertension (HT) is a cardiovascular disease with a high prevalence around the world. In Chile at year 2010 it reached $26.9 \%$ of the population. Objective: To determine salivary pH, buffering capacity, total proteins and salivary flow in controlled hypertensive diuretic users and a group without systemic diseases. Methods: 14 samples of unstimulated saliva of patients with hypertension treated with diuretics and 10 samples of unstimulated saliva of people without systemic diseases and not taking medication were analyzed. $\mathrm{pH}$, salivary buffering, salivary flow and total protein were determined in both groups. Results: The figures for the treated HT patients were as follows: pH: 6.83 , buffer capacity: 4.86, salivary flow: $0.55 \mathrm{ml} / \mathrm{min}$ and total salivary proteins: $1.09 \mathrm{~g} / \mathrm{dL}$. For those without systemic diseases the results were: $\mathrm{pH}: 6,88$, buffer capacity: 4,25, saliva flow: $1.8 \mathrm{ml} / \mathrm{min}$ and total salivary protein: $0.29 \mathrm{~g} / \mathrm{dL}$. No association was found between salivary flow ( $r s=0.425)$, buffering capacity $(r s=0.283$ ) and protein concentration $(r s=0.245)$ with the diuretic dose $(p>0.05)$. Statistically significant differences were found in salivary flow and total salivary protein concentration between the group with hypertension and without. (U Mann-Wthitney $\mathrm{P}>0.005$ ). No statistically significant differences in salivary $\mathrm{pH}$ and buffering capacity were found among the study groups (U Mann-Wthitney > 0.005). Conclusion: Patients with hypertension and treated with diuretics have a decreased salivary flow and an increased total protein concentration while ph and buffer capacity remained normal.

KEY WORDS: Salivary pH, salivary flow, buffer capacity, total protein, hypertension, diuretics.

\section{REFERENCIAS BIBLIOGRÁFICAS}

Banderas-Terabay, J. A.; González-Begné, M.; SánchezGarduño, M.; López-Rodríguez, A. \& Vilchis-Velázquez, A. Flujo y concentración de proteínas en saliva total humana. Salud Pública Méx., 39:433-41, 1997.
Ericsson, Y. Clinical investigations of the salivary buffering action. Acta Odontol. Scand., 17:131-65, 1959.

Fenoll-Palomares, C.; Muñoz Montagud, J. V.; Sanchiz, V.; 
MUÑOZ, L. S. \& NARVAEZ, C. G. pH salival, capacidad buffer, proteínas totales y flujo salival en pacientes hipertensos controlados usuarios de diuréticos. Int. J. Odontostomat., 6(1):11-17, 2012

Herreros, B.; Hernández, V., Mínguez, M. \& Benages, A. Unstimulated salivary flow rate, $\mathrm{pH}$ and buffer capacity of saliva in healthy volunteers. Rev. Esp. Enferm. Dig., 96(11):773-83, 2004

Gallardo, S. Diuréticos y betabloqueadores en el tratamiento de la hipertensión arterial. Rev. Peruana de Cardiología, 23(3):80-90, 1997.

Kaplan, M. D. \& Baum, B. J. The functions of saliva. Dysphagia, (8):225-9, 1993.

Ministerio de Salud (MINSAL). Encuesta nacional de salud 2009-2010. 2010

Ministerio de Salud (MINSAL).Guía Clínica Hipertensión Arterial Primaria o Esencial en personas de 15 años y más 2006, 2006.

Nedefors, T.; Twetman, S. \& Dahlöf, C. Effects of the thiazide diuretic bendrofhimethiazide on salivary flow rate and composition. Eur. J. Oral Sci., 97(6):520-7, 1989.

Preethi, B. P.; Reshma, D. \& Anand, P. Evaluation of flow rate, $\mathrm{pH}$, buffering capacity, calcium, total proteins and total antioxidant capacity levels of saliva in caries free and caries active children: an in vivo study. Ind. J. Clin. Biochem., 25(4):425-8, 2010.

Reverte Cejudo, D.; Moreno Palomares, J. J. \& Ferreira Pasos, E. M. Hipertensión arterial: actualización de su tratamiento. Inf. Ter. Sist. Nac. Salud, 22(4):81-94, 1998.

Screebny, L., Baum, B.; Edgar, W.; Epstein, J.; Fox, P. \& Larmas, M. Saliva: Its Role in Health and Diseases. Int. Dent. J., (42):291-304, 1992.

Zárate, D. A. N.; Leyva, H. E. R. \& Martínez, F. F. Determinación de $\mathrm{pH}$ y proteínas totales en saliva en pacientes con y sin aparatología ortodóncica fija (estudio piloto). Revista Odontológica Mexicana, 8(3):59-63, 2004.
Dirección para correspondencia: Carmen Gloria Narváez Carrasco.

Facultad de Odontología, Universidad del Desarrollo.

Barros Arana 1735,

Concepción,

CHILE

Teléfono 56-41-2268791

E-mail: cgnarvaez@udd.cl

Recibido : 29-11-2011

Aceptado: 07-01-2012 